\title{
Memory, oral history and conservation at Robben Island's Bluestone Quarry
}

\author{
Mwayi Lusaka
}

\begin{abstract}
This article is a critical examination of a conservation project on the restoration of the Stone Wall at Bluestone Quarry on Robben Island, a world heritage site. The project attracted different stakeholders with diverse interests. The Stone Wall was originally built by political prisoners in the early 1960 s as part of their hard labour. During the course of the project, issues relating to the authenticity of the Stone Wall arose which pointed to a conflict between cultural heritage and natural heritage on the site. The article focuses on the role of oral history as an approach to conservation and heritage management during the restoration project of the Stone Wall. It thus brings into the spotlight the role of memory-making in the conservation of historical fabric as well as the creation of cultural heritage. The central argument the article seeks to advance is that oral history and memory work helped to identify the appropriate design for the Stone Wall and thus improved the conservation of a significant historical site. Moreover, the memories of the ex-prisoners further enhanced the understanding and appreciation of symbolic meanings of suffering and triumph that the site embodies.
\end{abstract}

The conservation of cultural resources and heritage sites always involves the interpretation of the tangible and intangible elements of the site. It has been observed that the lack of proper methodologies of interpretation during conservation projects often leads to regrettable distortions of history. ${ }^{1}$ One methodology that is frequently used in the interpretation of heritage sites during conservation projects is oral history. In 2003, Robben Island Museum (RIM) used this methodology in its project to discuss the restoration of the washed away Stone Wall on Bluestone Quarry site. The Heritage Department of RIM established a reference group, known as Bluestone Quarry Reference Group, made up of ex-political prisoners who had originally worked on the Stone Wall in the 1960s. The project raised a number of challenges and problems that had to do with authenticity of the site and the conflict between the cultural and natural heritage on the site. Through memory work, the Bluestone Quarry Reference Group not only helped RIM in the interpretation and conservation of both the tangible

${ }^{1}$ See S. Herb, 'Effective Use of Authenticity and Integrity as World Heritage Qualifying Condition', City and Time, 2, 3 (2007), 123145 . 
and intangible significance of the Stone Wall but also provided the symbolic meanings that the site embodies.

This article explores and examines the use of memory via oral history in landscape interpretation and heritage management at Bluestone Quarry during the Stone Wall project. It does so through what Paula Hamilton and Linda Shopes have termed as 'ethnographic practice'. ${ }^{2}$ Thus it describes specific interviews and phases of the project and then reflects on these as 'artifact[s] of memory variously used in public to create, redefine and subvert a historical past'.3 Taking oral history and memory as its overarching framework, the article argues that oral history and memory work helped to identify the appropriate design of the Stone Wall and improved the way a significant historical site should be conserved. The memories of the ex-prisoners further enhanced the understanding and appreciation of symbolic meanings of suffering and triumph that the site embodied. The article also highlights, albeit implicitly, how the restoration project came to reverberate questions of nation building and identity of the South African nation. As the article will show, the way the ex-political prisoners expressed their sentiments, emotions and meanings of the site had implications on how they saw the project within the broader framework of South Africa's imagination as nation that has emerged through suffering and triumph.

The entire exercise of interviewing the ex-political prisoners lasted for four days, from 9 to 12 October 2003. All the interviews were recorded on voice recorders and audio-visual tapes. These recorded materials have been archived at University of the Western Cape and RIM Mayibuye archives. The audio-visual tapes deposited at the Mayibuye archives are largely in Xhosa language. However, two DVDs with English subtitles were produced and are in the custody of the Heritage Department of RIM. 4 With the help of a translator I analysed these tapes as well as the DVDs. The oral histories from the tapes and the DVDs have been supplemented with primary documents about the project and interviews with some of the stakeholders as I was not at any stage involved in the original research project.

\section{Making public pasts using oral history}

Memory work has been crucial and useful in the construction of heritage and public pasts. Further, it has helped provide meanings as well as interpretation of these constructed pasts and heritage. A brief comparative analysis of a few projects in the heritage and public history that have engaged oral history and how they relate to the Stone Wall project is a worthwhile undertaking.

Chrischene Julius has shown how oral history and memory work have been central to the museum-making and practices of District Six Museum. The District Six Museum works with the memories of the former residents of District Six in its curatorial practices.

\footnotetext{
${ }^{2}$ P. Hamilton and L. Shopes, eds, Oral History and Public Memories (Philadelphia: Temple University Press, 2008), xiii.

${ }^{3}$ Ibid.

${ }^{4}$ See A Robben Island Museum Kassified Production House, ‘The Bluestone Quarry’, DVD, 2 discs, 2013.
} 
She has demonstrated how the flagship exhibition of District Six Museum relied considerably on oral histories and testimonies in museum-making and curation. Thus the exhibition 'Streets: Retracing District Six', which marked the official opening of the District Six Museum, was made possible through the testimonies and memories of the former residents of District Six and their descendants. She has focused on how oral histories made the transition to texts by tracing the oral history processes of interviewing, translating, transcribing and exhibiting the text. She argues that oral history texts/transcripts accord authority to the exhibition. 5 This use of memory and oral history has some marked symmetries with how, as will be discussed later, RIM has relied on orality and memory in curating and 'museumising' itself as a heritage institution.

Noeleen Murray and Leslie Witz have shown how oral history was central to the whole museum project of Hostel 33 at Lwandle Migrant Labour Museum from its inception. Notably they have shown how the first project coordinator, Bongani Mgijima, 'planned that oral history-collecting would be the moving force of the museum and that exhibitions would [...] be the mechanism to gather more diverse recollections'. ${ }^{6}$ Thus, Mgijima had wanted the new museum to not only depend on objects but also on stories as part of the exhibition. The museum staff therefore embarked on theme identification, oral history interviews with subsequent translations, and transcriptions for curation and exhibition purposes.7 Describing the restoration and rehabilitation processes particularly in determining how the rooms should be compartmentalised and organised, they note that it was only when participants were divided into two groups to discuss and draw their visions for Hostel 33 on large sheets of paper that memories were sketched into reconstructing the hostel's past'. 8 The authors note that one group indicated that the hostels had changed over time, showing how initially there had been no separation between the compartments, then later how residents had installed self-made curtains for privacy, which became more permanent as partitions were hammered together using a variety of boarding and wood off-cuts, assembled into timber frame. 9

This approach to restoration by relying on memories of former hostel residents is similar to the use of ex-political prisoners to recount how the Stone Wall was built.

To emphasise strongly the relevance of orality and memory in the context of this article it is proper to demonstrate how it specifically works in the management of cultural resources that are landscapes or sites in nature as opposed to exhibition collections and the making of museums. David Harvey and Mark Riley have discussed how oral history methodology can engage with the fields of landscape archaeology and heritage studies.

\footnotetext{
${ }^{5}$ J. Chrischene, 'Digging Deeper than the Eye Approves; Oral Histories and their Use in the Digging Deeper Exhibition of the District Six Museum', Kronos: Southern African Histories, 34 (2008), 131.

${ }^{6}$ N. Murray and L. Witz, Hostels, Homes, Museum: Memorialising Migrant Labour Pasts in Lwandle, South Africa (Claremont: UCT Press, 2014), 118.

${ }^{7}$ Ibid., 119.

${ }^{8}$ Ibid., 36.

${ }^{9}$ Ibid.
} 
Working with the management of the heritage sites in Devon, Britain, they have shown how the oral history approach has engaged with aspects of landscape heritage. They have further explored the success of such an approach in terms of how oral history data can 'augment, destabilise and even challenge the existing scientific knowledge as well as offering alternative narratives'.10 In the case of the Stone Wall project, this article attempts to show that the memories of the ex-political prisoners provided a competing discourse to the discourse of the 'experts' and 'specialists' in heritage management.

Harvey and Riley have further charged that orality and memory have considerable potential for how we interpret and manage our landscape heritage, through offering a more nuanced and dynamic and rich account of the landscape that is seen as being far more than a collection of physical attributes and measurable artifacts. ${ }^{11}$

This observation is important when looking at how the memories of the ex-political prisoners during the Stone Wall project provided 'a more nuanced and dynamic rich account' of the site beyond its simple understanding as a site of labour.

Sean Field has noted how some places become the central point on which memories 'crystalise'. He has observed that in their daily lives, people interact with their spaces in various ways and after some time, due to particular events, such spaces and their memories become significant. In such situations, oral history becomes an invaluable tool. ${ }^{12}$ Field has therefore shown how the use of oral history is productive in the conservation and management of sites of memory and heritage. Through oral history, he has described how it was possible for the older people of Langa to identify sites of historical importance and suggest possible ways on how the intangible heritage embodied in historical accounts could be integrated with the tangible heritage as embodied in the physicality of the sites in conservation management of those sites. This has synergies in how, through oral history work, the Stone Wall project sought to integrate the intangible at Bluestone Quarry with its tangible heritage. In his analysis of oral history at Langa, Field came up with four guiding questions: 'how did imagining memories create and frame the telling of the stories within oral history dialogues?'; 'What histories were constructed through the memories and stories of the old people as individuals and as a collective group?'; 'How did the old people construct an emotional sense of connectedness to the site?'; and, finally, 'how the memories and histories gathered were used for the purposes of the project'.13 The first and third questions can help in analysing the oral history project at Bluestone quarry too.

\section{The Stone Wall project}

\footnotetext{
${ }^{10}$ D. Harvey and M. Riley, 'Landscape Archaeology, Heritage and the Community in Devon: An Oral History Approach', International Journal of Heritage Studies, 11, 4 (2005), 269-288.

${ }^{11}$ Ibid.

${ }^{12}$ S. Field, Oral History, Community and Displacement: Memories in Post-Apartheid South Africa (New York: Palgrave McMillan, 2012), 103.

${ }^{13}$ Ibid., 10.
} 
Robben Island has served various functions and purposes in different historical times. The indigenous Khoikhoi people originally inhabited it long before it encountered the European explorers. For nearly four hundred years, it has been a place of banishment, exile, isolation and imprisonment. ${ }^{14}$ Between 1961 and 1991, it served as a political prison for anti-apartheid activists. In 1994, with the birth of the democratic era and the spirit of the Mandela presidency, the island became a beacon of reconciliation. It was declared a national museum and heritage site in December 1996. The island was officially opened to visitors in January 1997 and work soon commenced on various infrastructural upgrades. In December 1999, the site was declared a World Heritage Site as a symbol of the 'triumph of the human spirit over adversity'.15

On the island there are different sites with different layers of histories. The quarries contribute to the history of the island. There are 20 quarries recorded on the site register database for the island. Many of these are concealed by vegetation and some have been filled in. ${ }^{16}$ The oldest quarry is the Jan van Riebeeck Quarry - or Jan se Gat (Jan's Hole) - situated on the southeast part of the island. The quarry was opened and extensively mined for slate at the time of Jan van Riebeeck from 1652, employing forced labour. The slate was used in construction works in the emerging European settlement at the Cape that today is Cape Town. This quarry continued to be worked intermittently for three hundred years until 1963 when it was closed. ${ }^{17}$

Another important quarry is the Limestone Quarry. It is a large excavation located inland, southwest of Murray's Bay Harbour. Lime was first quarried there during the Dutch colonial period. From 1963 political prisoners from the general section were deployed to work on it. Bluestone Quarry, which constitutes the focus of this article, is located in the north-western corner of the island and it is the site where both common law prisoners and political prisoners endured hard labour. It was first opened and operated by the political prisoners in 1963 for the mining of slate, also called bluestone. This was to meet demand for the stone used for cladding buildings on both the island and the mainland. ${ }^{18}$ Most of the bluestone for the construction of the maximum prison and network of roads on the island was extracted from this site from the labouring and suffering of these prisoners.

Before the prisoners started to work on the quarry, they built a Stone Wall or dyke to separate the sea from the quarry. This was because sea water, even under moderate tide, easily gained entry into the quarry, thereby disrupting operations on the site. The Stone Wall was made from the locally available materials on the site; for example, sand, sea

\footnotetext{
${ }^{14}$ H. Deacon, N. Penn and N. Alexander, Robben Island: The Politics of Rock and Sand (University of Cape Town, Department of Adult Education and Extramural Studies, 1993), 47.

15 H. Deacon, 'Intangible Heritage in Conservation Management Planning: The Case of Robben Island', International Journal of Heritage Studies, 10, 3 (2004), 1.

${ }^{16}$ Robben Island Museum (RIM), Heritage Department, Bluestone Quarry Documents, File 7/3/046/0005, 'Integrated Conservation Management Plan 2013-2018', 15 August 2013, 34.

${ }^{17}$ Ibid., 37.

18 South African Heritage Resources Agency (SAHRA) Archives, Robben Island Conservation Files, File 9/2/018/0004, 'Robert Sobukwe Complex Documents', 10 June 2011, 25.
} 
shells and beach pebbles. The prison authorities could have built a more permanent dyke but did not. The prison warders sadistically took pleasure at the prisoners' futile task of offloading sand and grit to buttress the dyke only for it to be later washed away by the waves. ${ }^{19}$

In 1978 all quarrying activities on the island ceased because of the pressure from the International Committee of the Red Cross which was advocating for the rights of prisoners. The Bluestone Quarry was consequently closed. However, the site was still looked after by the Department of the Correctional Services until they finally left the island in 1997, when RIM took over responsibility for its maintenance. ${ }^{20}$

In September 2001, a maritime storm destroyed a middle section of the Stone Wall resulting in the tide breaking into the quarry and creating a wide gap 15 metres wide. ${ }^{21}$ It was later severely damaged by the actions of sea waves. A 2002 survey found that the Stone Wall exhibited signs of general and progressive collapse. This was chiefly due to the combined effects of the application of heterogeneous building materials, building techniques and the sea. The fragility of the Stone Wall rendered it 'sensitive heritage' from a conservation perspective. ${ }^{22}$

As part of conservation management and in response to the degrading condition of the Stone Wall, in 2002 RIM contracted the Department of Public Works (DPW) to restore the Stone Wall. Among other plans, DPW recommended the placement of concrete cubes in a line along the shore to absorb the force of the sea. ${ }^{23}$ However, an independent survey carried out in May and August 2004 by an archaeologist, Edward Matenga, concluded that it was necessary to comply with international guidelines adopted by the UNESCO World Heritage Convention and affiliated organisations, such as the International Committee on Monuments and Sites (ICOMOS), on the treatment of places of heritage significance. Specific reference was made to the Australia ICOMOS charter for places of cultural significance, also known as the Burra Charter. Article 15 of this charter clearly stipulates that 'change may be necessary to retain cultural significance, but is undesirable where it reduces cultural significance'. It further provides that 'the amount of change to a place should be guided by cultural significance and its history'. 24

In the light of this, questions were asked by both the South African Heritage Resource Agency (SAHRA) and representatives of the ex-political prisoners who are members of the board of RIM about whether the new additions would retain the cultural/historical significance of the Stone Wall. The Stone Wall project became a contested one as it tried to

\footnotetext{
${ }^{19}$ UWC, Mayibuye Archives, Stone Quarry Tapes, Tape 14c, 12 October 2003; A Robben Island Museum Kassified Production House, 'The Bluestone Quarry'.

${ }^{20}$ This information was gathered during a conversation with Ron Viney, Conservation Consultant, with Ad Festina, 14 July 2014.

${ }^{21}$ SAHRA Archives, Robben Island Conservation Files, File 9/2/018/0004, E. Matenga, 'Proposals for the Conservation of a Dry Stone Wall at the Blue Stone Quarry on Robben Island', 15 May 2004, 10.

${ }^{22}$ Ibid., 11.

${ }^{23}$ Ibid., 12.

${ }^{24}$ Ibid., 15.
} 
find a middle ground to satisfy all the stakeholders that included environmentalists, heritage managers, engineers, SAHRA and the representatives of the ex-political prisoners.

For the ex-political prisoners, memory and history were at stake. The Stone Wall symbolised a historical marker of both their suffering and triumph during apartheid and therefore its significance had to be respected during the project. For them the authenticity of the Stone Wall was important. For the engineers the challenge was how to come up with designs for the Stone Wall that would respect its symbolic significance and be able to withstand the action of sea waves. SAHRA and the heritage managers were concerned with matters of observation and adherence to the principles and conventions of heritage and conservation management.

The environmentalists were hugely concerned with the impact of the designs of the Stone Wall on the biodiversity of the site, as some of the suggested designs adversely affected the marine life. The contestations around the Stone Wall Project were long drawn out. The debates commenced in 2002 and a resolution only emerged in 2014.

\section{The Bluestone Quarry Reference Group, memory and conservation}

In order to identify and select the ex-political prisoners who had worked on Bluestone Quarry the Heritage Department of RIM conducted a survey in 2002. The survey forms outlined different spans in prison and an ex-political prisoner was required to tick the box where he served his labour during the time of imprisonment. The prison records of the surviving prisoners after the closure of the maximum prison in 1991 were fundamental in tracing the whereabouts of the former prisoners. The Bluestone Quarry Reference Group was then formed in 2003. A total of 80 ex-political prisoners were invited to be part of the Bluestone Quarry Reference Group and participate in the interviews. Their age ranged from 60 to 90 years old. They were divided into two groups because RIM did not want a scenario where there was one clustered group. This was to avoid some individuals dominating the contributions over their colleagues. ${ }^{25}$

On 9 October 2003, the first day of the interviews and discussions, the ex-political prisoners forming the Bluestone Quarry Reference Groups were welcomed on the island. They were briefly introduced to the biography of the RIM and its mandated objectives. Members of the group in turn introduced themselves indicating the duration of time incarcerated on the island. ${ }^{26}$ They were then introduced to the project, its scope and objectives. It was emphasised to them that the project was part of the activities of conserving and managing the site.

For the oral history project at Bluestone quarry the interview questions were normally open ended and it was the facilitator from the Heritage Department who controlled the

\footnotetext{
${ }^{25}$ Interview with Nolubabalo Tongo, Senior Heritage Officer, RIM, Nelson Mandela Gateway, 28 April 2015.

${ }^{26}$ UWC, Mayibuye Archives, Stone Quarry Tapes, Tape 2C, 9 October 2003; A Robben Island Museum Kassified Production House,

'The Bluestone Quarry'.
} 
proceedings. In terms of the interview method, this was different to the one adopted by the 1997 Memory Project, where the interview guide sought to capture the life histories of the prisoners. In contrast, the approach to the Bluestone Quarry project was on life stories of the prisoners on the Bluestone Quarry site and not their life histories. It also focused on identification of important features on the site that had profound meaning to the ex-political prisoners. ${ }^{27}$ This was because the Stone Wall project was specific in nature and therefore the questions needed to be specifically focused on the site. These interviews were conducted on the quarry site itself where a marquee was pitched. I suggest this was owing to two factors. First, it was because the project was about site management and therefore it was proper to be on the site. Sean Field has referred to this approach as 'on-site interviews'. ${ }^{28}$ Second, this was a memory project and Bluestone Quarry was a 'site of memory' on which memories 'site of memory' on which memories of the prisoners resided. According to Pierre Nora, sites of memory are 'sites where memory crystalises and secrets itself and where a sense of historical continuity persists'. ${ }^{29}$

The most important feature on the first day of the interviews was the presentation of the suggested four designs of the Stone Wall by the engineers from the DPW. Since these designs were crucial for the entire project it is important to briefly describe them and the challenges that they engendered.

The first design option involved the reinstatement of the original Stone Wall with internal reinforcement which would be aesthetically integrated into the existing sections of the wall. In addition to restoring the integrity of the Stone Wall this option was meant to extend the lifespan of the wall as well as fulfilling the heritage requirements by visually integrating the existing sections of the wall. The second alternative also involved the reinstatement of the original Stone Wall with internal reinforcement that would be aesthetically integrated into the existing sections of the wall. However, to the south of the reinstated wall, a penguin ramp was proposed as an additional physical structure that would facilitate movement of the endangered penguins from the seaward side down to the quarry water. This was aimed to maintain the current movement patterns of the penguins. Unlike in design one where the penguin ramp was just a subtle gradient, in this design the ramp was a full physical structure that was clearly visible and seen as a new feature on the site.

Option three was quite different from the first two. It involved a mass concrete wall erected on the breached side but not aesthetically integrated with the existing sections of the Stone Wall. The aim of the reinstatement of the wall was to restore its heritage value attached as well as its integrity and original character. Lastly, the fourth design was a free-standing concrete wall positioned on the seaward side of the existing wall and

\footnotetext{
${ }^{27}$ UWC, Mayibuye Archives, Stone Quarry Tapes, Tape 2A, 9 October 2003; A Robben Island Museum Kassified Production House, 'The Bluestone Quarry'.

${ }^{28}$ Field, Oral History, Community and Displacement, 113.

${ }^{29}$ P. Nora, 'Between Memory and History', Representations, 26, 2 (1989), 8.
} 
not reinstating the Stone Wall. The option entailed that the constructed freestanding wall on the seaward side of Stone Wall would absorb the energy of the waves before reaching the existing wall.

After presenting the proposed designs, the Bluestone Quarry Reference Group was allowed to take a site survey around the quarry so as to determine the extent of the damage and be able to identify and remember other important spots and stories that would add meaning to and aid interpretation of the site. During this site survey, the ex-political prisoners started to react to the presentation. There were a number of concerns from the ex-political prisoners on the proposed designs of the project. The discussions and conversations that followed were never short of acrimony, emotions and anger from the ex-political prisoners. ${ }^{30}$

Mazabane Letsoko, an ex-prisoner who had served from 1963 to 1980, expressed his concern about the use of concrete materials as was the case with options two, three, and four: 'my worry is the concrete wall that [they] are going to build, is it going to be natural as we built the wall? My worry is the naturality of the wall.' ${ }^{1}$ Solomon Magapi Moetsi who served in the quarry in the years 1963 to 1973, shared similar sentiments: 'I want us to agree on one important thing. A solid agreement, a very important [one], on the question of let us protect the original pattern we made over there.'32 Melidin Pistoli, a prisoner from 1963 to 1978 , was more vocal but instructive when he recalled how they would restore the wall when it was washed away. His advice was to reconstruct using the same stones and not introduce other materials:

And the wall which we built when we were here must be rebuilt to reflect the exact same way it was. Because there are now parts, which are badly damaged. It should be started there because it was the same way even back then. We could keep rebuilding the damaged parts. 33

Other ex-prisoners, like Masiza Duru, whose imprisonment was from 1964 to 1966, were concerned with the proposed design of the new wall with full concrete walls and how it could affect the setting of the site. These were designs two, three and four. Duru explained:

My idea is that the concrete wall to be built here should not be as near as all that. It should be a little bit far from here because we still want the naturality of this, you see?34

\footnotetext{
${ }^{30}$ UWC, Mayibuye Archives, Stone Quarry Tapes, Tape 2B, 9 October 2003; A Robben Island Museum Kassified Production House, 'The Bluestone Quarry', disc 2.

${ }^{31}$ UWC, Mayibuye Archives, Stone Quarry Tapes, Tape 2A, 9 October 2003; A Robben Island Museum Kassified Production House, 'The Bluestone Quarry', disc 2.

${ }^{32}$ Ibid.

${ }^{33}$ Ibid.

${ }^{34}$ Ibid.
} 
The use of the phrase 'naturality of the wall' by the ex-prisoners hinged on the concept of authenticity or historicity of the wall. Thus, in their view, the proposed engineering interventions could not preserve the Stone Wall 'as it was' during their time. The same concern about maintaining what was 'original' was vented by two other ex-political prisoners Wongamo Ngqondela, who had been on the island from 1964 to 1973, and Raymond Masalo, who served his sentence from 1964 to 1966. Wongamo Ngqondela asked: 'Would [... it] not [... be] better for you to construct something almost the same as the wall?'35 Raymond Masalo provided some suggestions:

There should be a concrete wall built in front of the damaged wall to maintain the old one. I would also advise that the opening in the wall should be rehabilitated and strive to work it as when we worked on it so that when tourists come [they] should see the whole wall. 36

More miscellaneous inputs from the ex-political prisoners had to do with the need to protect some of the historical fabric on the site during the reconstruction of the Stone Wall. Others were appealing for the reinstatement of the road at the top of the quarry. The ex-political prisoners also felt that the stones that were part of the washed Stone Wall should be the main materials for reconstruction of the new Stone Wall.37

Many memories flowed about the Stone Wall in the prisoners' lives. Stanley Magoba, who was incarcerated on the island from 1963 to 1974, spoke of how he and others in 1964 constructed the Stone Wall:

The stone quarry is the bluestone, [it] is the kind of the stone that we used to build the prison. When you see the prison walls with the bluestones it is the stone that came out of here. So in recent time this prison was built by us here from the stone. We had to quarry that out from [a] special quarry because initially we had to build a dyke, to keep the sea out so that we could work on the stone. It took us about four to five months and a good part of winter season and rain[y] season. Because we could build up the dyke and Monday, Sunday, it rains, then it gets washed away. Then we start filling it up again with stone and sand while others are working on the quarry. Rebuilding the dyke was partly digging the rock and maintaining the dyke itself. ${ }^{8}$

His mention of the length of time it took to construct the wall and the prisoners' frustration at the wall being washed away repeatedly was a way to convey how the wall symbolises their suffering and torture. It was therefore a significant historical resource to regard with care during the project. Even though he did not mention how his account related to the proposed designs of the Stone Wall, I would argue that he wanted to stress

\footnotetext{
${ }^{35}$ UWC, Mayibuye Archives, Stone Quarry Tapes, Tape 3A, 10 October 2003; A Robben Island Museum Kassified Production House, 'The Bluestone Quarry', disc 2.

${ }^{36}$ Ibid.

${ }^{37}$ UWC, Mayibuye Archives, Stone Quarry Tapes, Tape 2A, 9 October 2003; A Robben Island Museum Kassified Production House, 'The Bluestone Quarry', disk 2.

${ }^{38}$ Ibid.
} 
the significance of the Stone Wall to the ex-political prisoners in the present times. Sean Field, drawing from Raphael Samuel, has argued that

for the interviewee the first purpose is not to describe the past as it was or even as it was experienced but to confer to the past experience a certain meaning, a meaning which will contribute the meaning of the present. 39

As suggested earlier, the Stone Wall is a monument that memorialises the birth of the new South African nation through suffering and triumph.

As a way of arguing for the preservation of the building materials, pattern and techniques of the previously washed Stone Wall, John Muhapa volunteered to demonstrate how they built the Stone Wall with the local materials. James Ben, a prisoner from 1964 to 1970, described the kind of stones that were specifically used for building and maintaining the Stone Wall.

It was emphasised by Zolire Keke, who served his sentence from 1964 to 1975, that it was their experience and imagination - and not certified engineering skills - that made it possible for them to build the wall. In this way the ex-prisoners established their importance through their knowledge. Their memories and experiences contrasted those of the 'experts' who were proposing new designs.

During the discussions much of the concern from the ex-political prisoners with regard to the proposed designs by the DPW clearly had to do with the historical authenticity of the wall. This was so important to them because of symbolic meanings of suffering and triumph that the perceived authentic wall embodied. It was this authentic wall that could ably narrate the story of the nation's suffering and its birth - hence its proper conservation. It is important at this point in the article to unpack what this concept of authenticity is all about and see why it was at the helm of contention during the project.

At the heart of the concept of authenticity is the essential consideration that there should be no doubt as to whether something was in the original site or structure and, in the case of the structure, that it represents original material and workmanship. Authenticity is a crucial aspect in the assessment of heritage resources and, generally speaking, authenticity is ascribed to a heritage resource that is materially original or genuine as it was constructed and as it has aged and weathered in time.40

Benard Feilden and Jukka Jokilehto have outlined the different aspects of authenticity that must be observed and respected when conducting any form of repair or restoration on cultural heritage resources. These aspects are authenticity in material, authenticity in workmanship, authenticity in design and authenticity in setting. They

\footnotetext{
${ }^{39}$ Field, Oral History, Community and Displacement, 35.

${ }^{40}$ S. Jones and T. Yarrow, 'Crafting Authenticity: An Ethnography of Conservation Practice', Material Culture, 8, 1 (2013), 17.
} 
have argued that any treatment that is planned for a monument or site should respect these criteria taken together. ${ }^{41}$

Another key issue in the identification, definition and conservation of a heritage resource is its integrity. Herb Stovel has defined integrity as the ability of a property to secure or sustain its significance over time. ${ }^{42}$ In simple terms, integrity addresses the questions: 'are all elements necessary to tell fully the story of the site? Is the cultural property of sufficient size to hold all features and processes necessary to convey significance?'43

Therefore the challenge for heritage practitioners, particularly those preoccupied with the conservation of cultural heritage resources, is how to retain the past that is embodied by buildings, sites and monuments while interventions necessary for their preservation require material change in the present. This situation can easily be noted during the restoration of the Stone Wall in terms of the proposed designs that were suggested by DPW and the subsequent rejection of such designs by the ex-political prisoners.

\section{Of suffering and triumph}

During the site survey there was more than method being described.The memory work on the site produced many accounts of the brutality of the warders and the harsh working environment, especially during winter. For those who worked in the 1970s, the warders Delport and the Kleinhans brothers loomed large because of their draconian supervision and treatment. Masuku vividly remembered the Kleinhans brothers:

Those two brothers were devils; they could not allow you to go and help yourself. I remember someone refused to say baas and he had a running stomach, he had to help himself with his trousers on and those devils will be laughing saying 'kyk hy kaak op sy broek' [Look he is shitting himself in his trousers].44

During cold winters Delport, the senior warder on the quarry, used to force the prisoners to face the direction of the cold wind so that they may catch the cold. Nape Matlala remembered this quite vividly:

As far as Delport is concerned, you see we were wearing short pants no underwears. Delport is a very cruel somebody. Now this place the weather changes now and again. He would put us up there knyplyn [breaking large stones into gravel] When cold air comes from this side, we must face this side. If cold air comes from that side, we must face that side. Now you are sitting on a small stone like this. This whole cold air gets into

\footnotetext{
${ }^{41}$ B. Feilden and J. Jokilehto, Management Guidelines for World Cultural Heritage Sites (Rome: ICCROM, 1998$), 66$.

${ }^{42}$ Herb, 'Effective Use of Authenticity and Integrity', 19.

${ }^{43}$ Ibid.

${ }^{44}$ UWC, Mayibuye Archives, Stone Quarry Tapes, Tape 14c, 12 October 2003; A Robben Island Museum Kassified Production House,

'The Bluestone Quarry', disc 2.
} 
you [pointing inside of the pants]. Then you are going to get sick. That is why many people got sick. 45

Torture and hardship at Bluestone Quarry took many forms. For some it took the form of chipping stone to gravel and from gravel to dust. Those who were in the wheelbarrow group had to transport huge stones from one place to another on sand, which made it difficult for an old rusted wheelbarrow to move in the sand. ${ }^{6}$ Khumalo recalled how brutally Delport 'the beast' beat his fellow prisoner Buyaphi because of failure to push the wheelbarrow:

We were over there near the wall. Buyaphi told me that he would not push the 'break my heart', because that was what we called the wheelbarrow, you know it was squeaky and hard to push in the sand. He showed me the blisters in his palms. Delport wanted him to still push the wheelbarrow. The devil saw that he could no longer make him push, he said let me give you a 'holiday' for tomorrow. Delport crushed the blistered hands with the shambook until Buyaphi cried like a baby. The following day he was 'on holiday' - he did not come because of the wounds. 47

Mzube and Roto, who worked the quarry in 1967, recalled a cruel doctor called Van der Berg. He would not attend to sick prisoners who were forced to work while ill and sometimes died as a result. Indres Naidoo could not forget how his colleague Masombo broke his back due to cruelty of a warder as the result of beating while carrying a load of stones in a bag. ${ }^{48}$ For prisoners like Zwelonke the Bluestone Quarry is synonymous with Robben Island as a prison. According to him that is where everything happened, he said:

the island was no other place but the quarry, not the cells, not the ugly vegetation, the quarry had become symbolical, the graduation centre, torture and the island, suffering and the island and that was the Bluestone Quarry.49

Many of the ex-prisoners testified how they turned their misery into an opportunity. They were able to teach and educate each other while on the quarry and some even graduated with bachelors degrees with the help of the education on the quarry. Many still pay tribute to the quarry because it is where they learned masonry skills, which helped them find employment when they left the prison.50 Some pointed to other notable 'sons' of the quarry who later became prominent in society, like the current president Jacob Zuma. ${ }^{1}$

\footnotetext{
${ }^{45}$ Ibid.

${ }^{46}$ Ibid.

${ }^{47}$ Ibid.

${ }^{48}$ Ibid.

${ }^{49}$ Ibid.

${ }^{50}$ UWC, Mayibuye Archives, Stone Quarry Tapes, Tape 2A, 9 October 2003; A Robben Island Museum Kassified Production House, 'The Bluestone Quarry', disc 2.

${ }^{51}$ UWC, Mayibuye Archives, Stone Quarry Tapes, Tape 14c, 12 October 2003; A Robben Island Museum Kassified Production House, 'The Bluestone Quarry', disc 2.
} 
These memories of cruel and brutal experiences were to underscore the value and meaning that the Stone Wall and the site embodied, a site of suffering and torture, and also a sight where defiance of the ex-political prisoners and the nation triumphed over evil. Thus, through recounting of their hardship, the ex-political prisoners sought to entrench the deeper meanings and value of the site other than being seen as place where they simply quarried stone.

\section{The significance of oral history and memory to the project}

The oral histories that were gathered in 2003 had a profound impact on the restoration project that was finalised in 2014. Not only did the oral history approach help in recovering the history of the site but it also enhanced its meaning and appreciation as an important place of memory and South Africa's history. As was observed during the interviews, more was reviewed beyond what the project had anticipated.

Histories were constructed from this oral history methodology through the memories of the ex-political prisoners. It became clear that the Stone Wall was built by the prisoners using locally available materials with no engineering instructions. It was also understood that Stone Wall and Bluestone Quarry were emblematic of the torture and suffering that the ex-political prisoners endured. Thus the Stone Wall was a monument from which they could remember their experiences of brutal and harsh labour during apartheid. This is why they rejected vehemently some of the proposed designs, as they would ultimately change the physicality of the Stone Wall and, in the process, its historical evidence of apartheid days. Through the memory work, the expolitical prisoners posited themselves as the 'experts', thus displacing the role of the engineers - who lacked history and memory. By suggesting the right techniques and materials for construction and the appropriate design, the ex-political prisoners sought to restore history to the site.

Here it should be mentioned that when the restoration project began in 2002, the main objective was only to conserve the Stone Wall and the site as a cultural/historical site. However, because of the biodiversity present on the site it was necessary (per the requirements of sections 23 and 24 of the National Environmental Management Act) to carry out surveys and basic assessments of the site in order to identify the impact of the project on the ecosystem and to suggest possible mitigation measures. When the survey findings were presented to the various stakeholders, debates and contests ensued among those who espoused environmental protection of the site, mostly the environmentalists, and those who defended cultural protection of the site, mostly the ex-political prisoners. Thus while the ex-political prisoners had rejected options two, three, and four of the designs due to their impact on authenticity, the environmentalists supported them - especially design option two, which had a penguin ramp proposed as an additional physical structure. Because the penguin ramp was a new feature to the wall that had never existed during the time of the ex-political prisoners there, it affected the site's authenticity and was therefore rejected by them, as the interviews in the article have shown. Such contestations among different 
stakeholders contributed to the protracted duration of the project. Among other factors that contributed to the length of the project were its complex nature and changes in RIM management, as well as budgetary implications $5^{2}$

It was in a focus group meeting on 25 February 2014, with all stakeholders present, including the representatives of the ex-political prisoners, that issues of the appropriate design for the project were eventually finalised. It was agreed that in order to maintain the symbolic meaning of the site and its history there should not be heavy concrete materials in reconstructing the Stone Wall and that the disturbed stones scattered on the site, once used by the ex-political prisoners, should be used rather than introducing new materials. It was also agreed that, as suggested by the ex-political prisoners, the proposed design should have no new additional material that might affect its historicity and authenticity. What this meant was that the building technique would be more like that of the ex-political prisoners. However, to reinforce the Stone Wall from further action of the sea, an internal concrete wall would be erected - this internal concrete wall would be covered with old stones so that it should not be visible.

It was after this last meeting in 2014 that a certificate was issued to authorise the implementation of the project.53 The remaining project phases are now the construction phase and the operation phase.54 The construction phase involves all construction activities to restore the Stone Wall while the operational phase includes all the maintenance activities once the Stone Wall is complete. The project does not have a decommissioning phase because 'the nature of this project dictates that the reinstated wall must be maintained for future generations and therefore the development has not been designated a lifespan'.55

As this article has shown, oral history and memory work presented suggestive ways of how a significant historical site could be conserved while at the same time preserving its symbolic meaning for the ex-political prisoners who laboured on it. Nolubabalo Tongo, the senior heritage officer of Robben Island, underscored the role played by the memories of ex-political prisoners during the conservation project. She acknowledged that without their memories they could not have come up with the conservation technique that was agreed on in the end. Instead, they may have gone with the popular design of putting dolosse 56 concrete structures or other heavy engineering material and in the process lose the historical significance of the site 57

\section{Conclusion}

\footnotetext{
52 Interview with Nolubabalo Tongo, Senior Heritage Officer RIM, Nelson Mandela Gateway, 28 April 2015.

${ }^{53}$ Interview with Pascal Taruvinga, Chief Heritage Manager RIM, Nelson Mandela Gateway, 28 April 2015.

${ }^{54}$ Ibid.

${ }_{55}$ See RIM, Heritage Department, File number 14/12/16/3/3/1/747, 'Reinstatement of the Blue Stone Quarry Wall and Limestone Road Way, Robben Island: Draft Environmental Management Programe', 13 March 2014.

${ }^{56}$ Dolosse are concrete blocks that are placed along the marine coast to break the sea waves.

${ }^{57}$ Interview with Nolubabalo Tongo.
} 
This article has demonstrated how crucial the use of oral history - through the memories of the ex-political prisoners - was during the conservation project at Bluestone Quarry on Robben Island. The Bluestone Quarry Reference Group proved to be an essential resource for research and memory processes in the Stone Wall project. The article has further shown how the ex-political prisoners' memories contributed to understanding and interpreting the tangible and intangible cultural heritage on the site and, in the long run, helped RIM to make informed interventions on the site. Even though the project drew stakeholders with different perspectives, the ex-political prisoners, through oral history interviews and their concurrent memories, shaped the decisions regarding the project. In particular, their contribution ensured that the restoration designs as suggested by the engineers of DPW/WSP and other activities should respect the notions of authenticity, integrity and cultural significance of the site. Through memory work, the ex-political prisoners were able to provide insight into the original building techniques, materials and setting of the site. This had a positive impact in modifying both the designs and the type of materials to be used in reconstructing the Stone Wall so that authenticity in design, material and setting could be retained. Apart from being used as a tool for recovering the history of the site as far as issues of authenticity were concerned, the oral history project provided nuanced meaning of the site in terms of its symbolic importance in post-apartheid South Africa. Thus the site is a monument to remember the suffering and triumph of the freedom fighters and it is also a crucible from which the new South African nation was born.

\section{Acknowledgements}

This paper has been adapted from my Masters' thesis entitled 'Conserving Spaces of Memory and Heritage: Complexities, Challenges and Politics of the Stone Wall Project at Bluestone Quarry on Robben Island', submitted to History Department of the University of the Western Cape in 2015. The Masters' research was supported by a fellowship from the Centre for the Humanities Research at the University of the Western Cape. 